\title{
“LENTIDÃO”, TERRITÓRIO E BEM-ESTAR: O MOVIMENTO DA CIDADE LENTA E A SUSTENTABILIDADE DO LUGAR
}

\author{
Rubens Moreira Rodrigues de Carvalho ${ }^{1}$
}

\begin{abstract}
RESUMO
O processo de urbanização vem contribuindo para que as cidades cresçam em ritmo acelerado, sem um planejamento adequado às finalidades sociais e de modo desigual. Esse tipo de crescimento, por sua vez, afeta a qualidade de vida da população e o meio ambiente, tornando os sistemas urbanos pouco eficientes. Para viabilizar interesses capitalistas, cidades, produtos e valores humanos foram transformados em mercadorias. Com isso, conceitos como sustentabilidade e bem-estar passaram a ser incorporados aos processos de empresariamento do solo urbano, justificando e incentivando o consumo de lugar. Os hábitos sociais do meio urbano, cada vez mais concentrados no "ter", também ajudam a denunciar as incoerências do atual modelo de desenvolvimento econômico, que se pauta na exploração irresponsável e ilimitada de pessoas e recursos naturais. Nesse trabalho, vamos expor iniciativas que buscam meios de fazer da cidade um lugar melhor para se viver. São iniciativas que almejam afirmar modos de vida alternativos, mais focados na sustentabilidade do meio urbano e no bem-estar social. Para isso, não se prendem somente nas tecnologias ecoeficientes e apontam, como diferencial, a importância da cultura local na construção de cidades sustentáveis.
\end{abstract}

PALAVRAS-CHAVE: Sustentabilidade. Bem-estar social. Cidade Lenta (Cittaslow).

\section{"SLOWNESS", TERRITORY AND WELFARE: THE SLOW CITY MOVEMENT AND THE SUSTAINABLE PLACE}

\begin{abstract}
With the process of urbanization, the cities are growing rapidly, creating an urban area with a high degree of spatial fragmentation and social segregation. This growth also affects the quality of life, the natural environment and the urban systems. In the capitalist world, cities and all human products were transformed into commodities. Thus, sustainability and welfare (like many other human concepts) are used to promote the commercialization of urban land. To sustain the consumerism and the demands of consumer society, it is necessary to exploit people and natural resources in an irresponsible and unlimited mode. In this paper, we will discuss interventions that seek to establish alternatives to a sustainable urban development. To make a city a better place to live, with sustainability and welfare,

\footnotetext{
${ }^{1}$ Mestre em Arquitetura e Urbanismo pela Universidade Federal Fluminense (PPGAU/UFF), Aluno de Doutorado do Programa de Pós-Graduação em Arquitetura e Urbanismo pela Universidade Federal Fluminense (PPGAU/UFF). Email: rubens.mrc@hotmail.com
} 


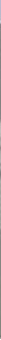

em áreas urbanas. No Brasil, por exemplo, o grau de urbanização alcançou a marca de $84 \%$, segundo dados do IBGE (2010). Projeções indicam ainda que, nas três próximas décadas, o planeta deverá passar pelo maior e mais rápido processo de urbanização da história humana, com reflexos negativos, sobretudo, para os países de economia emergente (HERZOG, 2013).

Devemos considerar também que a cidade, para o ideário social, representa um espaço de oportunidades, com mais possibilidades de oferecer conforto à vida da população - garantindo sustento econômico, serviços e infraestrutura adequada e opções de lazer e entretenimento - do que no campo. As pessoas migram para as zonas urbanas, portanto, com a esperança de encontrar nas cidades as supostas condições de emprego e moradia que desejam. Mas a realidade que encontram, no entanto, não costuma ser condizente com a imagem idealizada, pois as intervenções que mais poderiam contribuir para a qualificação da ambiência urbana ${ }^{2}$ acabam não sendo voltadas para todas as cidades ou para toda a cidade.

O iminente crescimento urbano (territorial e populacional) e a acentuação da crise ambiental, que denuncia a degradação irresponsável dos recursos naturais e abala relações políticas e econômicas globais, impõem para o século XXI o desafio de evitar o colapso dos sistemas que sustentam a civilização humana. Para vencer essa disputa, no entanto, será preciso priorizar soluções que permitam conciliar com justiça, respeito e eficiência - as pessoas, a natureza e as demandas do meio urbano e do desenvolvimento econômico. Quando os processos e as estruturas que dão forma, função e sentido ao urbano puderem ser ordenadas segundo princípios éticos e sustentáveis, poderemos encaminhar, com maior coerência, as intervenções sobre o território, as dinâmicas sociais e as necessárias quebras de paradigma.

Como o território urbano tem sido organizado praticamente em função dos interesses econômicos, as cidades passaram a reproduzir, a consolidar e a acentuar uma série de conflitos e tensões socioambientais. São problemas inerentes à lógica econômica vigente, que comprometem a eficiência dos serviços e da infraestrutura urbana, afetam a qualidade de vida da população e caracterizam as cidades como

\footnotetext{
${ }^{2}$ Podem ser considerados exemplos de intervenções capazes de melhorar a ambiência e o ambiente urbano: a oferta de moradias dignas e saudáveis para todos, a preservação e a coerência no manejo dos recursos naturais, a eficiência e a disponibilidade da infraestrutura oficial, a mobilidade urbana adequada e a distribuição ordenada dos postos de trabalho, dentre outros.
} 


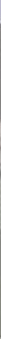

modelos insustentáveis sobre inúmeros aspectos. Nesse contexto, as pessoas e os recursos naturais são explorados sem qualquer restrição e, como consequência, o espaço urbano passa a ter baixa qualidade social e ambiental, consumindo grandes quantidades de energia e matéria, gerando equivalentes quantidades de resíduos e poluentes e dificultando a preservação das áreas verdes e a integração do homem com a natureza (HERZOG; ROSA, 2010).

Podemos dizer, portanto, que, para atender aos interesses capitalistas, as cidades foram transformadas em mercadorias e hoje, com o incentivo e a conivência de políticas públicas, priorizam somente as ações de reprodução e acumulação do capital. Nesse contexto, conceitos como sustentabilidade e bem-estar, por exemplo, são utilizados para favorecer o empresariamento do solo urbano, agregando valor econômico aos espaços, justificando o consumo de lugar e permitindo a ocupação e a comercialização de áreas com relevante interesse ambiental. Aspectos que, sobre outras apropriações, deveriam apenas qualificar a ambiência urbana, com a lógica capitalista, ajudam a produzir cidades territorialmente segmentadas e socialmente desiguais.

Auxiliado pela globalização, que vem tentando consolidar a estandardização das culturas globais, o capitalismo fez da cidade um lugar de consumo e do modo de vida urbano uma cultura pautada na prática do consumo. Segundo Lipovetsky (2007, p. 109), vivemos em uma era em que todas as esferas da vida social e individual se encontram, de alguma forma, reorganizadas segundo a ordem consumista. Sobre essa conjuntura, as cidades funcionam como economias de serviços avançados e tudo aquilo que as compõe, seja material ou imaterial, adquire potencial para ser transformado em mercadoria. Para Acselrad (2013, p. 237), a cidade se tornou "o lugar preferencial da realização do consumismo de bens. Mas também, vale dizer com o advento do urbanismo competitivo - é o lugar do consumismo de lugares".

Lotufo (2011) afirma também que o atual modelo de valor, muito baseado num consumo irresponsável, tem como medida de riqueza apenas a aquisição de bens. O que contribui para que a heterogeneidade dos valores individuais possa ser subvertida pela lógica capitalista, dando lugar à homogeneidade do consumismo e dos desejos coletivos. Para Lipovetsky (2007, p. 111), esta seria, inclusive, uma das maiores consequências da globalização, pois quando as resistências culturais caem 


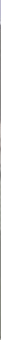

Reside nessa última finalidade, por sinal, um dos maiores problemas da equação, pois quando os processos do meio urbano se realizam de modo a priorizar os interesses econômicos, sobre o objetivo máximo do lucro, expõe-se à crítica a incoerente contradição existente em uma proposta de desenvolvimento ilimitado que se pauta numa fonte de recursos finitos (FRANCO, 2001). Para Lotufo (2011, p. 111), muito se fala da importância que o meio ambiente e a sociedade deveriam ter para os processos de desenvolvimento, mas o problema, no entanto, é que o modelo capitalista em vigor não tem por costume considerar os capitais humanos e naturais envolvidos nesses processos.

Muitos dos problemas que atingem as cidades e degradam a ambiência urbana, como o alto acúmulo de lixo, a grande emissão de poluentes, a degradação da vegetação e dos corpos hídricos, a falta de segurança, a distribuição iníqua de serviços e da infraestrutura e a difícil mobilidade urbana, dentre outros, estão, de algum modo, ligados à difusão do consumismo em nossas sociedades. Segundo Herzog e Rosa (2010), quando cidades se consolidam sobre esses estigmas, elas trazem, em vez de sustentabilidade, novos conflitos socioambientais.

Sustentabilidade, no entanto, é um conceito muito amplo e que ainda pode ser mais detalhado. Mesmo estando relativamente desgastado, por ter sido utilizado nas últimas décadas em associação a qualquer produto, objeto ou valor humano (dando nome até a partidos políticos!), ele é uma bandeira forte dos movimentos ecologistas e ambientalistas, que desde os anos 1970 vêm contestando de modo intrínseco as bases desse desenvolvimento predatório. Ao buscar a conscientização da sociedade sobre os impactos de suas ações no meio ambiente, ambientalistas e ecologistas estão contribuindo para que a sustentabilidade se torne um ideal mais presente e atuante na estruturação de cidades e sociedades, diminuindo o "cinza" e ressaltando o "verde" nos processos urbanos.

Mas, afinal, como podemos identificar uma cidade sustentável? Se a cidade sustentável realmente existe - ou pode vir a existir - quais são os seus princípios básicos e de que forma esses princípios podem contribuir para qualificar a vida e a ambiência urbana? Em linhas gerais, a cidade será considerada sustentável quando permitir a implantação das diretrizes do desenvolvimento sustentável, garantindo a sobrevivência da geração presente, sem comprometer a sobrevivência das futuras 


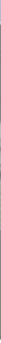

gerações. Para isso, a cidade precisa se aproximar da sua autossuficiência e deve utilizar todo o aparato técnico e tecnológico disponível para se tornar mais eficiente, para reduzir seus impactos, gerar menos resíduos e interagir de modo harmônico e mais equilibrado com o meio ambiente, preservando a biodiversidade e a identidade cultural de cada local.

Segundo Herzog (2013, p. 107), o objetivo (e o principal desafio) da cidade sustentável é promover a inserção da biodiversidade na malha urbana e em todos os lugares possíveis. Para isso, deve se pautar num conhecimento científico que leva em consideração os fluxos e os processos naturais locais no planejamento urbano. Para a autora, quando as cidades conseguem preservar os seus recursos naturais e valorizar as suas áreas verdes, possibilitando uma maior integração destas com as atividades humanas, abre-se caminho para a sustentabilidade e para criação de uma ambiência mais qualificada para a vida humana.

A integração das áreas verdes com as estruturas urbanas, no entanto, para ocorrer de modo equilibrado, nos exige uma maior consideração sobre as demandas e as prioridades de cada um desses sistemas. Na cidade ecológica e sustentável, o "verde" dos recursos naturais é que deve assumir o papel de qualificar a ambiência, dando mais eficiência aos sistemas naturais das áreas urbanas e promovendo, por exemplo, o conforto térmico, a redução da poluição, a qualificação da infraestrutura e a valorização da paisagem. Ao respeitar e tirar maior proveito das particularidades territoriais e ambientais de cada local, a cidade sustentável rompe com paradigmas tradicionais do planejamento urbano e faz com os recursos naturais não sejam tão negligenciados, ignorados ou subvertidos pela malha e pelos processos urbanos.

Para Herzog (2013), a reparação dos sistemas naturais do meio urbano, que hoje encontram-se invisíveis, sobrevivendo em estado fragmentado e altamente prejudicado, poderia criar vibrantes sistemas antropogênicos capazes de orientar o desenvolvimento das cidades pelo caminho da sustentabilidade. A autora afirma que a formação de espaços multifuncionais, em contraposição à monofuncionalidade de grande parte das estruturas urbanas (como as ruas, por exemplo, que são pensadas quase sempre de modo a priorizar o fluxo de veículos), pode ser alcançada através de uma proposta de recuperação dos recursos naturais e do aprimoramento da chamada "infraestrutura verde" das cidades. 


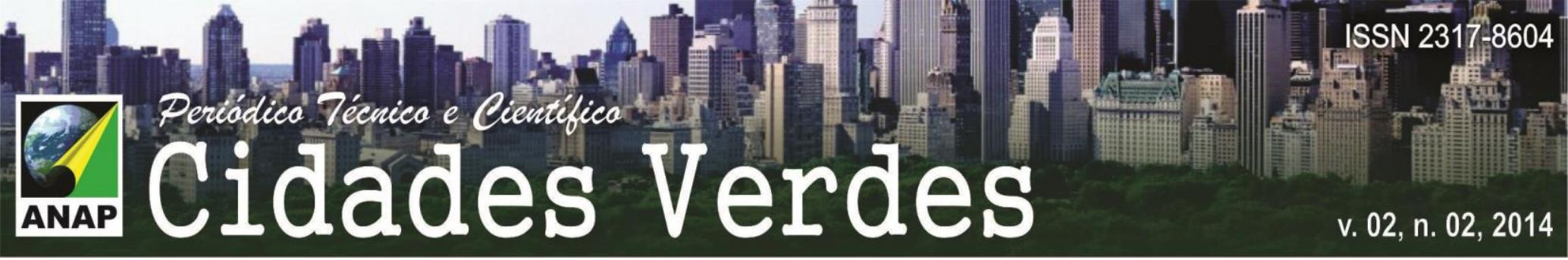

Essa "infraestrutura verde", a que se refere a autora, corresponde à soma dos fragmentos permeáveis e vegetados das zonas urbanas, podendo incluir as ruas e também as propriedades públicas e privadas (HERZOG; ROSA, 2010, p. 97). Seu grande diferencial é a sua capacidade de integrar os sistemas naturais aos sistemas urbanos, através de redes multifuncionais e interconectadas, permitindo a criação de cidades mais ecológicas. Com isso, as cidades se tornam não só mais sustentáveis, como também mais resilientes às alterações climáticas e às consequências trazidas pelo desenvolvimento econômico.

Uma das maiores contradições na proposição de cidades sustentáveis, no entanto, é que grande parte das intervenções e das inovações propostas por elas não podem ser desassociadas do domínio capitalista e dos interesses econômicos do desenvolvimento. Como carregam uma imagem positiva, que tem a ver com uma maior consciência e uma maior responsabilidade sobre os impactos do homem no meio ambiente, elas passam a ser mais valorizadas economicamente também. Com isso, abre-se a possibilidade para que a sustentabilidade do projeto seja subvertida e o conceito passe a ser utilizado somente para favorecer o empresariamento do solo urbano e para justificar o consumo de lugar.

Quando um determinado empreendimento traz como diferencial conceitos associados à sustentabilidade, ele se torna um grande objeto de desejo (e de desejo de consumo) da sociedade. Com isso, ele passa a ser vendido como um produto ideologicamente correto, que é mais eficiente, mais durável, menos impactante, que respeita o meio ambiente e ainda é capaz de oferecer melhores condições de vida e promover o bem-estar de seus usuários. Por conta disso, os empreendimentos ditos sustentáveis assumiram uma condição de excelência no mercado imobiliário e hoje atraem cada vez mais investidores (públicos e privados), interessados em direcionar os seus produtos ao público economicamente mais qualificado para arcar com os custos (e custear os lucros) desse tipo de proposta.

O empreendimento que está sendo construído na periferia de Abu Dhabi, capital e também o maior de todos os Emirados Árabes Unidos, é um exemplo que pode nos elucidar melhor essa forma de apropriação comercial da sustentabilidade. 


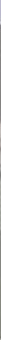

Masdar City está sendo vendida como uma nova "cidade- jardim", como um modelo de assentamento que pode ser infinitamente reproduzido e como um projeto capaz de provar que a cidade sustentável é uma utopia possível. No entanto, ela pode ser encarada também como mais um dos megaempreendimentos de luxo que são elaborados para os milionários dos Emirados Árabes, pois não traz políticas de integração social e está sendo construída a partir de equipamentos públicos de alta qualidade e de prédios caros e luxuosos. Como agravo, o projeto tem sido rotulado como uma brilhante estratégia de marketing do governo local, que vem tentando ofuscar os verdadeiros impactos do seu modelo de desenvolvimento econômico, que é totalmente baseado na exploração do petróleo.

Para esse tipo de empreendimento, a sustentabilidade é mais do que uma justificativa e pode trazer também uma significativa economia de capital. Em Masdar City, a maior parte dos recursos financeiros necessários para a sua execução estão vindo de empresas privadas. O governo local, que idealizou o projeto, vai dispender apenas de um quarto do investimento total e ainda poderá recuperar grande parte desse capital ao final do processo, através da venda de créditos de carbono.

Podemos dizer enfim que, apesar dos benefícios que traz para a sociedade, a sustentabilidade também pode ser utilizada para outros fins. Para fazer com que a cidade se torne efetivamente sustentável - sem que o respeito ao meio ambiente e à vida humana impeça o sustento econômico - precisaremos rever as bases do atual modelo de desenvolvimento. Criar, isoladamente, produtos ecoefientes ou de baixo impacto, não vai resolver de fato o problema. Para que a sustentabilidade se torne um conceito eficaz no mundo de hoje, a ecologia, a resiliência, o equilíbrio, o bemestar, a justiça e outros termos similares, devem ser incorporados como prioridades pelas políticas que conduzem a produção e a reprodução de nossas cidades.

\footnotetext{
${ }^{5}$ Howard ficou famoso ao propor, ainda no início do século $X X$, soluções urbanas e regionais em busca da sustentabilidade das cidades. A "cidade-jardim", como ficou conhecida, era um modelo de assentamento com limite populacional controlado, baseado na mescla da cidade com o campo (town \& country) e totalmente cercado por cinturões verdes que tinham a função de conter a expansão urbana e fazer a transição com as paisagens produtivas (HERZOG; ROSA, 2010, p. 96). Apesar de nunca ter sido materializada exatamente como concebida, a "cidade-jardim" acabou influenciando de modo significativo o planejamento urbano do século XX, com inúmeros reflexos inclusive no Brasil.
} 


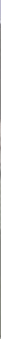

por conta das poderosas ações de marketing que acompanham a política econômica dos Estados Unidos.

Difundido globalmente, como parte de um processo de (de)formação cultural internacional, o fast food acabou se tornando um ícone da cultura do consumo e tem sido muito associado ao estilo de vida urbano. Nas cidades globais, a "rapidez" não está só na alimentação e envolve praticamente todas as atividades humanas, o que favorece a homogeneização cultural e a dominação econômica dessas sociedades. Para Schlooser (2001), o fast food assumiu o seu grau de perversidade ao atingir o âmago das culturas locais: sua comida, o quê, onde e como comer.

O movimento do Slow Food (Comida Lenta, em livre tradução), como indica o próprio nome, é uma oposição crítica aos resultados da globalização. Nasceu em 1986, na Itália, como um manifesto contra a industrialização, a economia global e o consumo desenfreado. Seu fundador, Carlo Petrini (2001, In: MAYER; KNOX, 2006), ao protestar contra a abertura de uma lanchonete McDonalds ao lado da Piazza di Spagna (Praça de Espanha), em Roma, visava proteger o "direito de provar", dando mais valor à comida local, ao prazer de se sentar à mesa e à adoção de um ritmo de vida mais "lento", sempre em virtude do bem-estar social.

Em 1989, o Slow Food se tornou internacional e hoje tem representação até no Brasil. O movimento luta para reduzir os impactos socioambientais da produção e, para isso, procura incentivar o crescimento das economias locais, em oposição ao global. Valoriza, portanto, o território e as práticas comunitárias, incitando o consumo de alimentos mais saudáveis, que possam ser produzidos localmente, com respeito ao meio ambiente e à vida dos animais (SLOW FOOD, 2004).

O Slow Food foi quem serviu de inspiração para o Cittaslow (movimento da Cidade Lenta) e, apesar desses dois movimentos terem objetivos diferentes, suas abordagens podem ser consideradas complementares, defendendo o convívio social harmônico e a "desaceleração" das atividades humanas como forma de promover o bem-estar. Conforme Knox (2005, p. 6), o Cittaslow foi concebido em 1999, quando Paolo Saturnini, prefeito de Greve in Chianti (pequena cidade da região da Toscana, na Itália), se reuniu com os prefeitos de outros três municípios locais (Orvieto, Bra e Positano), para definir os atributos que poderiam caracterizar a Cidade Lenta. 


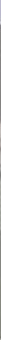

A maior preocupação da reunião, eram os efeitos da globalização na cultura local. Por conta disso, foram definidos princípios e diretrizes que buscavam valorizar sempre a qualidade, no lugar da quantidade. Os compromissos assumidos desde o primeiro encontro, portanto, estavam direcionados à formação de um ambiente mais calmo, menos poluído e mais ajustado às finalidades humanas de conforto e bemestar. Para isso, as políticas precisariam dar vitalidade à economia local e incentivar a adoção de soluções administrativas que valorizem a vida. Para Knox (2005, p. 6), o Cittaslow é um movimento que defende a boa comida, a construção de ambientes saudáveis, a sustentabilidade econômica e a sazonalidade e o ritmo tradicional da vida em pequenas comunidades.

De fato, ao apresentar alternativas para o desenvolvimento local, a Cidade Lenta se torna mais sensível e mais receptiva às metas econômicas, ambientais e sociais do desenvolvimento sustentável. Com isso, o movimento se ajusta à lógica do sistema econômico dominante, assumindo seu caráter de realidade, e não perde os seus diferenciais, pois pode seguir promovendo a sustentabilidade e valorizando a cultura e a equidade social de comunidades locais (CITTASLOW, 2011).

Hoje, o Cittaslow é uma organização não governamental, com atuação em países da Europa, América e Ásia. Sua filosofia constituiu um estatuto próprio, com práticas e políticas a serem implementadas - e constantemente aprimoradas - pelas cidades que desejam se tornar "lentas". Totalmente voltado para a escala municipal, o movimento se restringe aos municípios com menos de 50 mil habitantes. Para seu fundador, Paolo Saturnini (In: RUSCHEL, 2012), cidades pequenas estão mais aptas a proporcionar o estilo de vida promovido pelo movimento, pois necessitam apenas preservar (paisagens, espaços, costumes e etc.) para manter a qualidade, enquanto que cidades grandes, por estarem em um estágio de desenvolvimento urbano mais avançado e possuírem "mais de uma alma", precisariam revolucionar para promover a qualidade.

Em sua essência, o movimento da Cidade Lenta valoriza o protagonismo comunitário, a agricultura orgânica, a pureza da matéria-prima e a fruição da vida em um ambiente saudável, coibindo o avanço da globalização e a padronização cultural. A Cidade Lenta, portanto, não ignora as tecnologias ecoeficientes, mas procura ir além do que elas podem oferecer, destacando a importância da diversidade cultural 


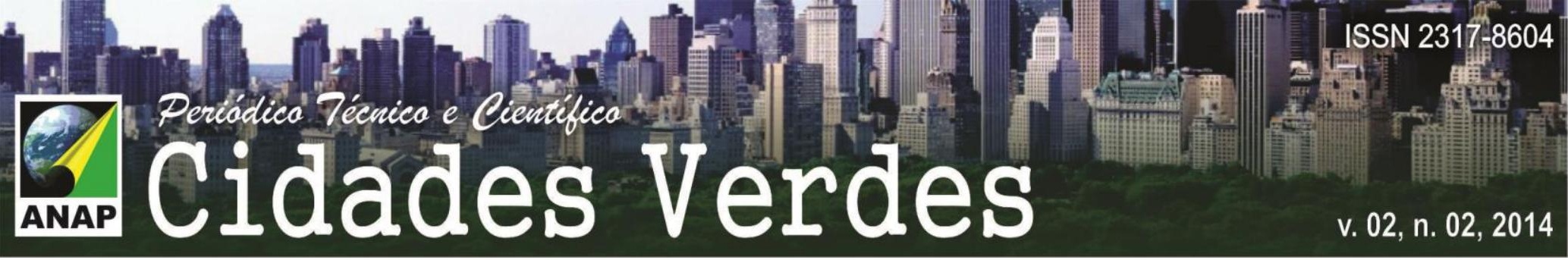

REDE DA SUSTENTABILIDADE (2007). Sustentabilidade. Disponível em: <http://www.sustentabilidade.org.br>. Acesso em: Maio 2007.

RUSCHEL, Rogério (2012). Cittaslow: a revolução urbana que respeita a alma. Envolverde: Jornalismo e Sustentabilidade. Disponível em: <http://envolverde.com.br/economia/entrevistaeconomia/cittaslow-a-revolucao-urbana-que-respeita-a-alma/>. Acesso em: 10 abr. 2014.

SCHLOSSER, Eric. Fast Food Nation. Penguin Books, 2001.

SLOW FOOD (2004). All about slow food. Disponível em: <http://www.slowfood.com/>. Acesso em: 20 maio 2014.

TRIGUEIRO, André. Mundo Sustentável: abrindo espaço na mídia para um planeta em transformação. São Paulo: Globo, 2005. 